\title{
Study on Incentive Issues in Enterprise Training Based on External Economic Theory
}

\author{
Jing Xinxin \\ School of Finance, Zhongnan University of Economics and Law, Wuhan, 430073, China
}

Keywords: Corporate Training; External Economy; Employee Motivation.

\begin{abstract}
As a key part of modern enterprise management, the importance of staff training is selfevident. How to improve the training efficiency and reduce the turnover rate of employees is always an important issue for managers. However, due to differences in learning efficiency among different employees, and the behavior of a single employee may create hidden additional benefits to other members, even if there is a training-related incentive system within the enterprise, it is often difficult to obtain the expected training effect. Based on the external economic theory, combined with the reverse-phase-out theory and human resource training, this paper analyzes the motivation issues in enterprise management that are directly related to employee training so as to enhance the training for efficiency, to achieve the desired effect to provide a theoretical reference.
\end{abstract}

\section{Introduction}

Staff training is an essential link in business management. Reasonable and effective training mechanism has a positive effect on productivity growth. Therefore, employee training in modern business management occupies more and more resources. However, with the continuous routine and specialization of corporate training, a series of negative problems have not been effectively solved. The most prominent problem is that trainee workers are trained as training providers after acquiring skills and knowledge The original employer of the party was reduced to a training platform for competitors and a great deal of resources were wasted. Modern human resource management technology is maturing, system design to enhance training effectiveness and reduce the turnover rate of trainees is increasingly rich, such as the signing of long-term labor contracts or noncompetition agreements, but because of the different constraints faced by enterprises, some in a specific environment BOC effective system is often difficult to apply to other enterprises, so to establish their own training system has become the basic consensus of business managers.

In order to establish an effective employee training system tailored to the specific circumstances of the enterprise, managers first need to clearly identify the key issues that hinder the successful implementation of the training. Limited by the total amount of resources, identifying and addressing key issues can achieve the stated objectives at the lowest cost. In general, employees with higher learning efficiency and ability are expected to receive higher benefits after training, and the loss of such employees after training is even more detrimental to the business. Therefore, it is necessary to separate the highly efficient trainees from all the trainees and conduct a separate study so that they can grasp the key foothold of the training system and lay the foundation for a higher level of system design in the next stage.

In addition, trainee as a member of the organization, its personal ability will affect the income of other members of the organization, the resulting externalities effect will fundamentally affect the trainee's utility function and decision-making behavior, which is to build the basic foothold of the incentive mechanism related to training is that if the external economy cannot clarify the mechanism of decision-making by the trainees, especially the highly efficient trainees, and exclude the negative distortions of the external economy on the incentive system at the system design level, it will inevitably be difficult achieve good training effect. At present, the researches on corporate training risk mainly focus on the identification of corporate human capital investment risk and the establishment of employee loss prevention mechanism after training. Few researchers have discussed the related issues in corporate training from the perspective of externalities. Teece D J 
analyzed the risk of vocational training for landless peasants during rural labor transfer from the perspective of externality [1], noting that externalities and asymmetric information may distort the supply and demand of labor training, Which is of some reference for the follow-up study. However, the research is based on the field of public administration and has limited guidance on enterprise training. In addition, more and more scholars believe that the incentive system should be closely linked with the training system. For example, Gafiyatullina A Z et.al. advocate the establishment of an "incentive and restraint platform" and "provide employees with a platform for further development to reduce post-training loss Rate "[2]. At the same time, some scholars such as Kozlenkova I V te.al. have realized that the incentive system may also be affected by some factors that" the incentive mechanism will fail when the information is asymmetric [3]. The existing literature lays a theoretical foundation for this study, but since neither of them analyzed the behavior of highly efficient employees in enterprise training and the failure of related incentive from the perspective of the external economy, so it left room for theoretical expansion for this study.

In summary, the trainee with high efficiency is considered as the main research object. Besides, the external economic theory is considered as a foothold in this paper, combined with the theory and methods of reverse supply and human resources training theory, to conduct the enterprise management training and employee training directly related to the incentive mechanism analysis. This study is expected to provide a theoretical reference for managers to improve training efficiency and achieve the desired effect.

\section{High Efficiency Trainee Correlation Analysis}

\subsection{High Efficiency Trainees General Behavior Patterns and Related Issues}

This paper defines efficient trainees as trainees whose learning ability or learning effect is significantly higher than the average. Because of the objective differences in intelligence among individuals, for any multi-person organization, the existence of such relatively efficient trainees and their often higher expectation of post-training benefits than those of ordinary trainees encourage managers to target the differentiated needs of highly effective trainees in developing training mechanisms. Figure 1 depicts the possible patterns of behavior of highly efficient trainees in different situations, with the dashed rectangles representing the various problems they may face, the solid boxes representing the decisions that may eventually be taken, and the sign behind that indicates that the decision is at Under normal circumstances will have a positive or negative impact on employers' businesses.

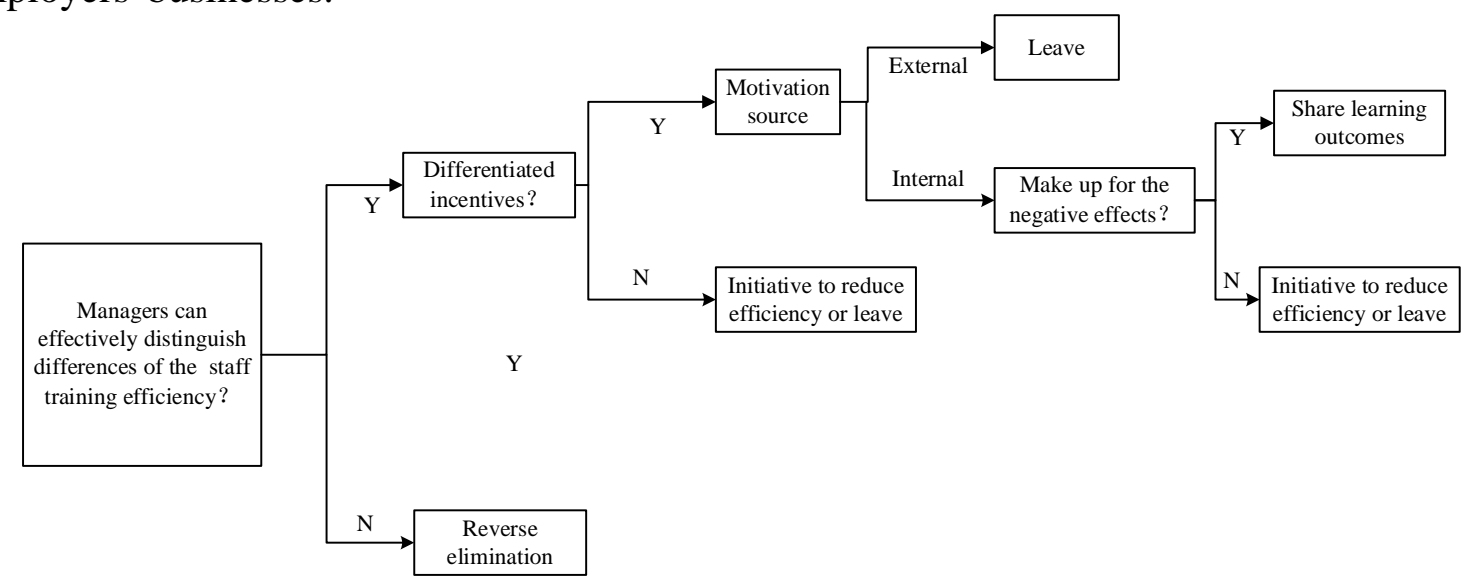

Fig.1 High Efficiency Trainee Decision-Making Behavior Diagram

First, it can be seen from Figure 1 that managers need to be cautious in many aspects to enable efficient trainees to make business-friendly decisions, whereas the negative sign at the back of the figures indicates that trainees are more likely to be disadvantaged As a result, managers and managers have great risks. Only by taking into full consideration of various explicit or implicit factors can we design the most efficient system. 
Second, Figure 1 also shows four issues managers and efficient trainees face together:

Whether managers can effectively differentiate trainees with different learning efficiency. This problem is the basic problem managers need to solve, but also easily overlooked issues. Many training programs do not introduce appropriate assessment mechanisms to assess trainees, which is particularly common in daily training. Because of the asymmetric information and the lack of measures by managers to eliminate this asymmetry, managers tend to treat all trainees equally and provide no noticeable difference in incentives for training. At the same time, the undifferentiated incentives, subject to cost constraints, will be based on the average level of trained staff. However, as highly efficient trainees have above-average expected returns, they face a lower-than-expected level of returns and the group will tend to make business-friendly decisions such as switching to other businesses after acquiring new skills or Take the initiative to reduce learning efficiency and so on. Eventually, highly efficient trainees will gradually be eliminated by regular staff with only general competence. Therefore, managers should first solve the problem is essentially the problem of asymmetric information.

Whether to provide differentiated incentives. Employee Incentives are the foundation of every business, but the general Incentives and Employee Incentives are not always tightly integrated, and are only stimulated if employees are given immediate access to additional benefits as they acquire new skills It takes full advantage of training opportunities to enhance individual competence and contribute to the motivation of the business. Although many managers distinguish between trainees of varying efficiency, they are often constrained by a variety of factors that do not allow trainees with higher personal skills to receive the material returns or room for improvement that eventually lead to the latter being disadvantaged Decision-making.

Where do the trainees face the motivation? Managers face two situations. One is that one's own side fails to provide the corresponding differentiated incentives, but the one from external competitors can provide incentives that meet the expectations of efficient trainees. The other is that neither one's own nor one's outside forces can do so. In the second scenario, the trainee is likely to take the initiative to reduce the investment in learning resources, because continue to work will outweigh the benefits, but in the same industry and cross-market competition is increasingly fierce environment, the first case The odds are significantly higher.

\subsection{Impact of External Economy on Trainee Behavior}

The economic behavior of a single consumer or producer can have a positive or negative impact on the welfare of other economic actors and cannot be reflected in market prices where the utility provider has not traded from the market In the case of adequate compensation, there is the so-called externality [4]. If the impact is positive, it is called the external economy, otherwise, it is the external diseconomy. This theory was originally proposed by Marshall, the neoclassical economist, and economists such as Lackéus $\mathrm{M}$ and Williams Middleton $\mathrm{K}$ continued to refine and apply it extensively to economics research and public policymaking [5]. On the other hand, the representatives of the new institutional economics such as Coase argue that the transaction characterized by the establishment and maintenance of contracts exists widely within the enterprise. For enterprises, the connection between different departments of different individuals [6]. The tangible and intangible contract, this series of internal transactions is also an alternative to market transactions. Therefore, it is reasonable to regard a certain enterprise as a microcosmic market, in which individual members are the economic actors in the market [7]. Individuals seeking to maximize their utility may lead to the external economy or not.

Taking an efficient trainee worker a as an example, its hard work training will bring it private value (earnings) $V p$, while facing a downward-sloping private marginal revenue $M R$ (Figure 2). The employee's ability to exceed the average can have several positive effects on the other members of the organization. First, employees who acquire new skills or new knowledge can objectively improve the overall work efficiency of the organization. Secondly, by sharing the learning outcomes, Establish learning benchmarks, create a competitive atmosphere, etc., efficient staff can have a positive impact on other members of the organization. Therefore, there is an external 
economy in the corporate training process, and the organization's return $V o>V p$. The organization faces a right-downward slope of the marginal revenue curve $M O B$ higher than $M R$. The marginal external benefit $M E B=M O B-M R$, this variable is the extra benefit that other trainees bring to the benefit of highly effective trainees while pursuing their own benefits. Since the cost of learning does not significantly increase at the same pace as the individual's ability to improve, one can assume that the private marginal cost MC (for training) stays the same, in fact, even if the MC is tilted to the upper right without affecting the final analysis.

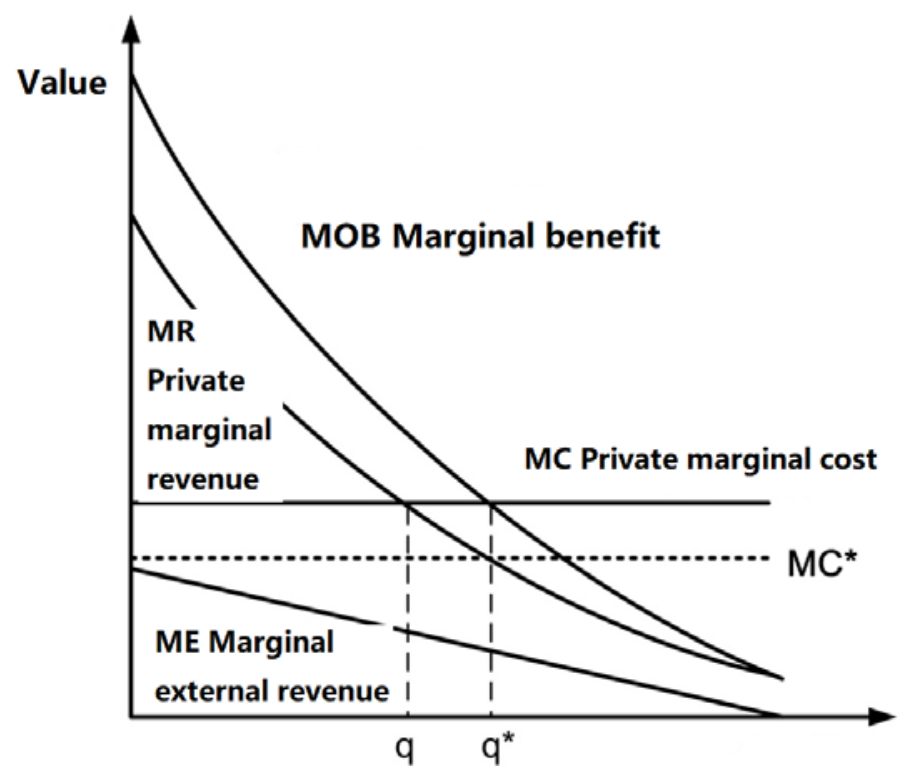

Fig.2 External Economic Principle of Action Diagram

On the one hand, if there is no incentive in the organization for both individuals and outsiders to achieve above-average personal abilities through training, the benefit to Employee $A$ is likely to be less than the cost, when $V p<C p(C p$ is private cost and $C p<V o$ ), the revenue is less than the cost, so A will not seriously accept the training. If $\mathrm{A}$ is conscientiously trained, the other members receive a return $(V o-V p)$ because $V o>C p>V p$, so $V o-V p>C p-V p$, indicating that other members have the ability to carry out A without compromising their own interests Compensation, which led to A's profit is greater than the cost, and then take action in favor of the whole.

On the other hand, if A's level of motivation is such that $V p>C p$, A will act to maximize its personal income, but the external economy will hinder A's "production" enough personal capacity to maximize the benefits of the entire organization, which When the incentive system fails and can not maximize the benefits of the organization. In Figure 2, the equilibrium point $\mathrm{A}$ faces is determined by the intersection of $M R$ and $M C$, and the corresponding personal ability is $\mathrm{q}$, that is, for A, it only needs to raise the personal ability to the level of q, beyond which It is difficult to obtain enough revenue to make up for the learning costs (effort, time, etc.). But for the organization, the optimal equilibrium point is determined by the intersection of $M O B$ and $M C$, and the corresponding level of capability is $q^{*}$. As a result, the external economy led to A's lack of personal capacity growth to maximize the benefits of the entire organization, with a margin of $\left(q^{*}\right.$ q). As long as A's learning behavior benefits others, $M O B$ is always higher than MR, and $q^{*}-q$ is always greater than zero.

Organizations can increase A's personal productivity output to $q *$ by lowering its private marginal cost to $M C *$, such as providing more advanced learning aids to A, or arranging for more convenient accommodations for A, reducing its Time to go to the training center. In addition, it is also possible to make up for the loss of $A^{\prime}$ 's personal ability to $q *$ directly through material or spiritual reward. Promoting position $A$ to move the private marginal revenue level $M R$ to the upper right (and not to cause MOBs to move in sync as most of the members will have a hard time gaining through $A$ 's promotion) also increases the equilibrium value to $q^{*}$. If the above incentives are from the outside, $A$ will most likely switch to another business or organization. If the income 
inequality in the external economy cannot always be compensated, the highly efficient trainee will regard the other members as "free riders", that is, other people may obtain additional benefits but will not be able to compensate themselves, and therefore take the initiative Reduce efficiency or leave.

\section{Management Advice}

Based on the aforementioned research, it is derived that the external economy will have several problems:

Firstly, the external economy may distort the incentive mechanism so that the incentive mechanism cannot achieve the desired results. If the incentive system ignores the fact that other members of the organization gain additional hidden benefits through efficient trainees, it may result in highly effective trainees being able to visualize other employees as "free riders" and feel "taken advantage of" and thus refuse to cooperate with other Members to share knowledge and eliminate their potential to promote the large-scale growth of organizational efficiency.

Secondly, under the influence of external economy, there is a difference between the optimal personal decision-making and organizational optimal decision-making of highly efficient trainees. The optimal individual equilibrium level is always less than the optimal organizational equilibrium, that is, the need for change is often reflected in the fact that employees are not familiar with the skills or knowledge they are trained in, and are not willing to devote more effort to in-depth study, though this can bring greater benefits to the enterprise.

In the face of external economic problems, managers can take the following strategies:

Firstly, there is a need to proactively identify employees with different learning abilities and learning outcomes and to provide highly motivated trainees with specific incentives to feel that the benefits of new acquisition skills or knowledge outweigh the costs of learning, and thus their willingness to promote individuals Ability to prevent the reverse phase-out of highly efficient staff. In management practice, external incentives are greater than those provided within the organization, and highly efficient trainees may flow to rival companies. If there is no effective incentives both in and out of the country to make their benefits outweigh the costs, then highly efficient trainees will take the initiative to reduce their learning efficiency as their workload or responsibility will continue to grow as their personal abilities increase. If earnings have not been compensated Cost, reduce their own efficiency is the best decision. Therefore, managers should establish a special incentive mechanism that is different from the general incentive system. That is, incentives and training are closely linked so that the highly efficient employees can realize that their new acquisition skills can outweigh the costs and the net benefits Higher than other less efficient employees.

Secondly, we should establish the awareness of the external economic issues and recognize the various problems that the external economy may cause. This is the basis for solving the external issues.

Thirdly, motivate highly effective trainees to contribute sufficient personal power to the organization by increasing the individual's marginal revenue levels, reducing marginal costs, and direct compensation. In practice, managers can provide more efficient training staff with more advanced learning tools to reduce their learning costs, such as the deployment of new laptops, etc .; also provide them with additional training due to traffic, data acquisition, etc. cost. It is important to emphasize that managers should be committed to enabling efficient trainees to perceive that they make an additional contribution to the organization while getting adequate compensation. Attempts to link the material gains with the knowledge output of efficient trainees. For example, conditional payouts may be set up for efficient trainees, where the best trained staff should share the knowledge of the other members to help improve the other members, Gains (eg, collective year-end awards, sales revenue, etc.) earn a percentage of royalty; commitments can also be made to them, providing promotion opportunities as long as the team's performance reaches a certain level, but this should be indicated to them Direct compensation that makes additional contributions to other members. 


\section{Conclusions}

High-efficiency trainees may make decisions that are detrimental to employers' enterprises in various aspects. The main problems they may face are whether their own above-average learning efficiency can be identified by their managers or whether they can obtain incentives from inside the enterprises, and this incentive is closely related to the new acquisition skills; and whether the obtained incentive can compensate for the negative effect caused by the external economy (that is, whether the incentive system is effective). In practice, managers should first sort out all aspects of training in accordance with this context, and examine the existing system in which areas there are deficiencies, from the external economy, reverse phase-out and other daily training of human resources easily overlooked issues to build complete and effective staff training system.

The existence of an external economy in the training of enterprises, and the efficient trainee to pursue their own interests to maximize the behavior of the direct or indirect ways to make the other members of the organization benefit. On the one hand, efficient trainees can improve the work efficiency of the whole organization directly through higher individual ability, so as to reduce the workload of other members with the same workload; on the other hand, they can also share the learning outcomes and establish learning Benchmarks, creating a competitive atmosphere and other indirect ways to promote other members to improve efficiency

\section{References}

[1] Teece D J. A dynamic capabilities-based entrepreneurial theory of the multinational enterprise [J]. Journal of International Business Studies, 2014, 45(1): 8-37.

[2] Gafiyatullina A Z, Nikonova T V, Vagin S G, et al. Organization of controlling the intellectual potential of company personnel[J]. Review of European Studies, 2015, 7(4): 13.

[3] Kozlenkova I V, Samaha S A, Palmatier R W. Resource-based theory in marketing [J]. Journal of the Academy of Marketing Science, 2014, 42(1): 1-21.

[4] Masalimova A R, Nigmatov Z G. Structural-functional model for corporate training of specialists in carrying out mentoring [J]. Review of European Studies, 2015, 7(4): 39.

[5] Lackéus M, Williams Middleton K. Venture creation programs: bridging entrepreneurship education and technology transfer [J]. Education+ Training, 2015, 57(1): 48-73.

[6] Azevedo C L B, Iacob M E, Almeida J P A, et al. Modeling resources and capabilities in enterprise architecture: a well-founded ontology-based proposal for ArchiMate[J]. Information Systems, 2015, 54: 235-262.

[7] Damiani M, Pompei F, Ricci A. Family Firms and Labor Productivity: The Role of Enterprise-Level Bargaining in the Italian Economy [J]. Journal of Small Business Management, 2016. 